\title{
HIV/AIDS: The Challenges and the Opportunity for Small Countries
}

The regional studies presented in the previous chapters clearly demonstrate that, despite the differences among countries from various regions of the world, the HIV/AIDS epidemic follows a pattern in which its impact is so similar that it can be discussed independent of any region or country.

In examining the three previous chapters, there are some clear similarities. Indeed, the framework and scope of all three focus on the impact HIV/AIDS has had on the economies of countries in each respective geographic location. It is interesting that the fight against the spread of the disease employs virtually similar tactics. What is more, the impact of the epidemic was shown to have similar implications for all regions although they are practically poles apart.

We can classify the impact of HIV/AIDS under three main areas, which were clear from the information presented, and outline the similarities that emerge from each region. These are discussed in the following sections.

\subsection{The impact of HIV/AIDS on the demography of countries}

The impact of HIV/AIDS on population size and growth is especially significant for small countries. Globally, we see from the information presented in Table 1.1, that the daily HIV/AIDS-related mortality rate can be computed as close to 5,500 persons in 2008. Given the fact that the sub-Saharan Africa and Caribbean regions rank first and second respectively, in terms of HIV prevalence, the prospective mortality implications for the countries concerned are clear. As we saw in chapter 1 , in the Caribbean region the mortality rate in the second decade of HIV/AIDS, that is the 1990s, increased by more than 500 per cent! This follows the global trend in AIDS-related deaths, which also recorded a phenomenal increase during the same period. Although not explicitly outlined in the sub-Saharan Africa study, it can be readily deduced that the region must have had a similar experience given the rapid rate at which a low prevalence state was converted into one of high prevalence, as well as the fact that, as shown in Table 1.2, countries in this region account for approximately 66 per cent of all HIV/AIDS cases globally. While the transition in incidence of the epidemic moved from among core groups to being generalised in the population may not be unique to small countries, the impact on smaller countries is likely to be more significant.

A second point of similarity among the three regions is the fact that the epidemic has enveloped the 15 to 44 years age group, which in most countries accounts for the highest number of persons living with HIV/AIDS. This is a similarity which results from the character of the virus and its main transmission methods. This group represents not only the primary members of the labour force, but also the population cohort that is usually expected to carry on with the procreation needs of the society. In a situation where more and more women are falling prey to HIV/AIDS, there would be implications for the fertility rates of countries. This, when combined with the high rates of mortality, results in a decrease in both the size and growth rate of populations. 
When one analyses the entire picture, it would be reasonable to expect a change in the structure of populations in which the working or productive age groups are decreasing relative to the non-working age groups. The traditional population pyramids would no longer apply since the top of the pyramid, which represents the 60 years and older age group, will expand, while the middle of the pyramid, which represents the 15 to 45 years age group, will contract. Figure 5.1 is a projection of the population for Trinidad and Tobago (a small country within the Caribbean region) for the year 2025 that was extracted from the US Census Bureau's population pyramids. It takes into account AIDS mortality although we have not portrayed the without-AIDS scenario.

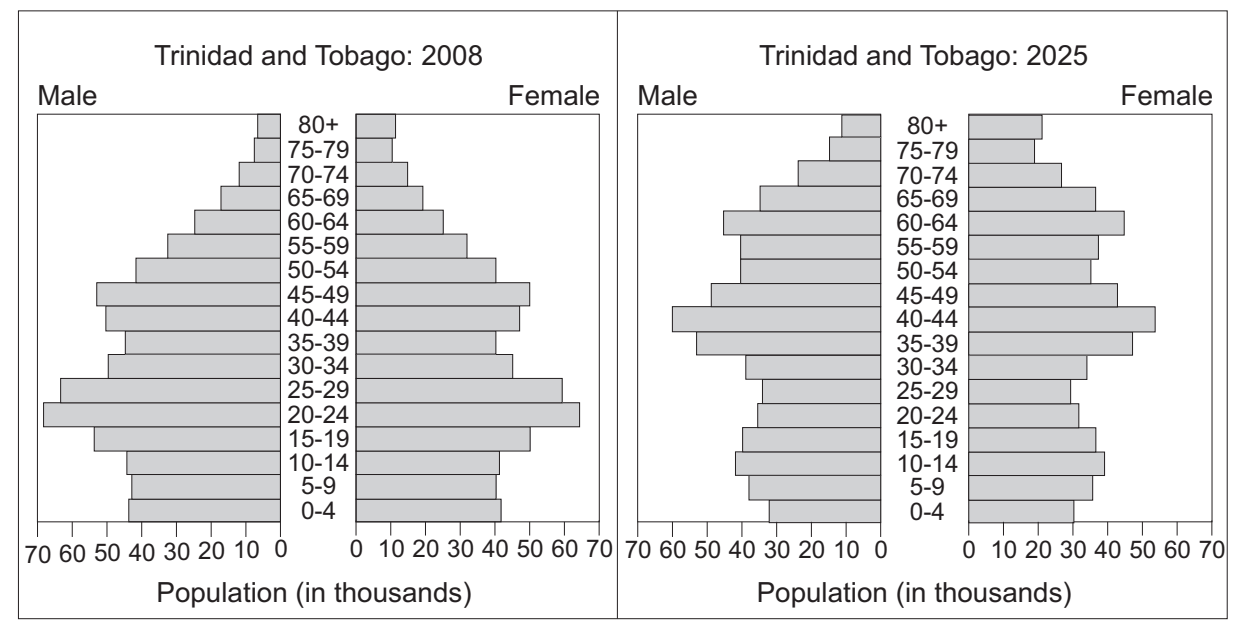

Figure 5.1 Projected size and structure of population with AIDS for Trinidad and Tobago, 2008-2025 Source: US Census Bureau, International Data Base. Available at http://www.census.gov/cgi-bin/ipc/idbpyrs.pl? Cty=TD\&out=s\&ymax=200\&submit=Submit+Query

For comparative purposes and to demonstrate the impact of HIV on the structure of populations, the pyramids for Botswana (a country in sub-Saharan Africa) are shown in Figure 5.2.

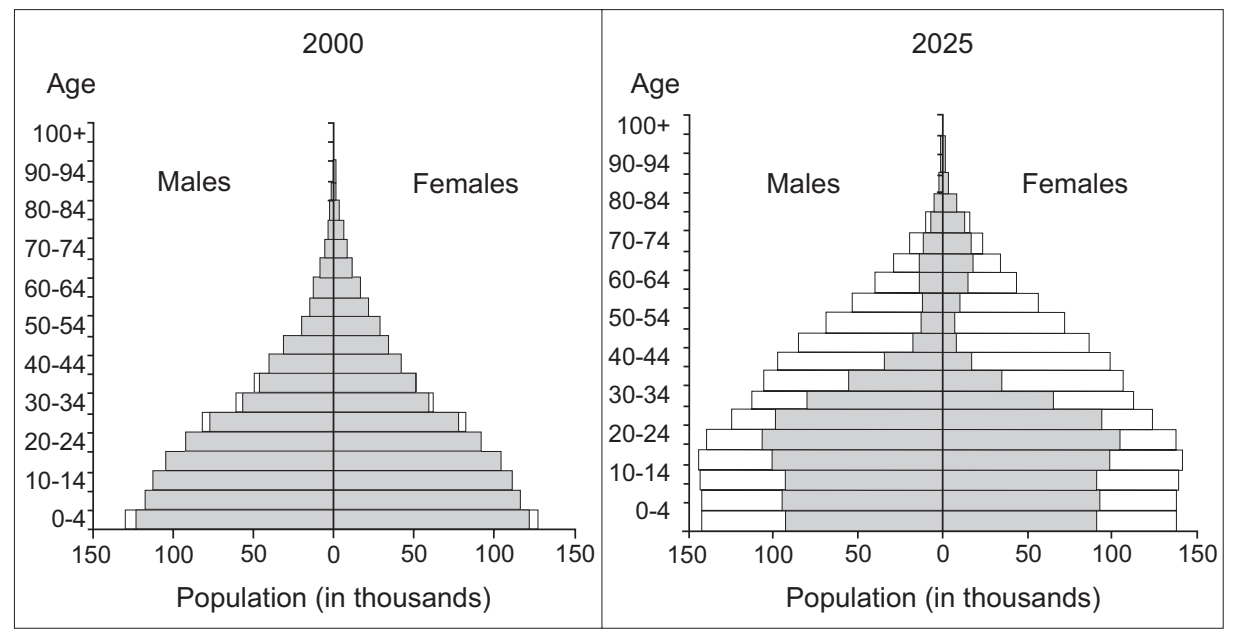

Figure 5.2 Population size and structure with and without AIDS for Botswana, 2002-2005 Note: Inclusion of the unshaded areas indicates the population size without AIDS. Source: DESA (2005) 
The projected population for Botswana with HIV/AIDS shows a middle-aged population (taken as people aged between 30 and 50 years) that is virtually disappearing, which signals a relatively small labour force. In the case of Trinidad and Tobago, the situation is not as severe, although a similar trend emerges especially when one looks at the younger age groups between 15 to 35 years.

\subsection{The extinction concern}

As mentioned earlier, the presence of the HIV/AIDS epidemic in small-population societies raises the very serious concern of population extinction. In the Caribbean, for example, the prevalence rates are now in the vicinity of only 2 per cent, but the reality is that countries in the sub-Saharan region converted from low single-digit prevalence rates to high double-digit rates in less than two decades. This is a scenario which the small countries of the Pacific and the Caribbean have to keep in mind. Compounding the damage to the development gains of these regions will be the real possibility of reduction in the populations in these regions to levels no longer viable. The prospect of a persistent non-decreasing HIV/AIDS incidence in a small population is one which makes a mockery of any development effort in these countries.

President Festus Mogae of Botswana has declared that his nation, after living with HIV/AIDS for many years, was actually facing obliteration due to AIDS. 'The impact of HIV/AIDS on the population, the economy, and the very fabric of our society not only undermines development, but poses a serious threat to our security and life as we know it. ... We really are in a national crisis', Mogae told Reuters in an interview that year. 'We are threatened with extinction. People are dying in chillingly high numbers. We are losing the best of young people. It's a crisis of the first magnitude.'(Garrett, 2005)

\subsection{The impact of HIV/AIDS on development}

The ability of HIV/AIDS to reverse and erode the development gains realised by countries in the past is not in question. The book has shown that the epidemic has the potential to reduce economic growth, deepen poverty, reduce life expectancy, and increase infant mortality.

One of the singular features of HIV/AIDS is its concentration in the 15 to 45 age group in most countries and certainly for those in the Caribbean, Pacific islands and sub-Saharan Africa. Obviously, the ability of the regions to improve economic growth and development is likely to be weakened as productive members exit the labour force due to morbidity or death. Productivity will also be affected by decreased levels of morale in the surviving labour force and an increased number of new, inexperienced workers. A lowering of the growth potential is almost inevitable.

From the Caribbean study, we saw that for Guyana and Suriname, two countries of the Caribbean region, HIV/AIDS was projected to have a negative impact on GDP, savings, investments, employment and the labour supply. In Guyana, what was expected was a decrease in GDP by approximately 2.73 per cent due to HIV/AIDS, while in Suriname the expected decrease was 1.18 per cent (McLean, 2004). Similar negative trends are projected for the other countries of the region.

Life expectancy also has a distinct impact on a country's long term pool of human capital and on the overall morale and 'spirit' of its population. What this study has shown is that the countries in sub-Saharan Africa have recorded significant decreases in life expectancy values since the onset of HIV/AIDS in the 1980s. As Figure 5.3 illustrates, Botswana, one of the countries with the highest levels of HIV prevalence worldwide, in the first decade of the new century has a life expectancy of 


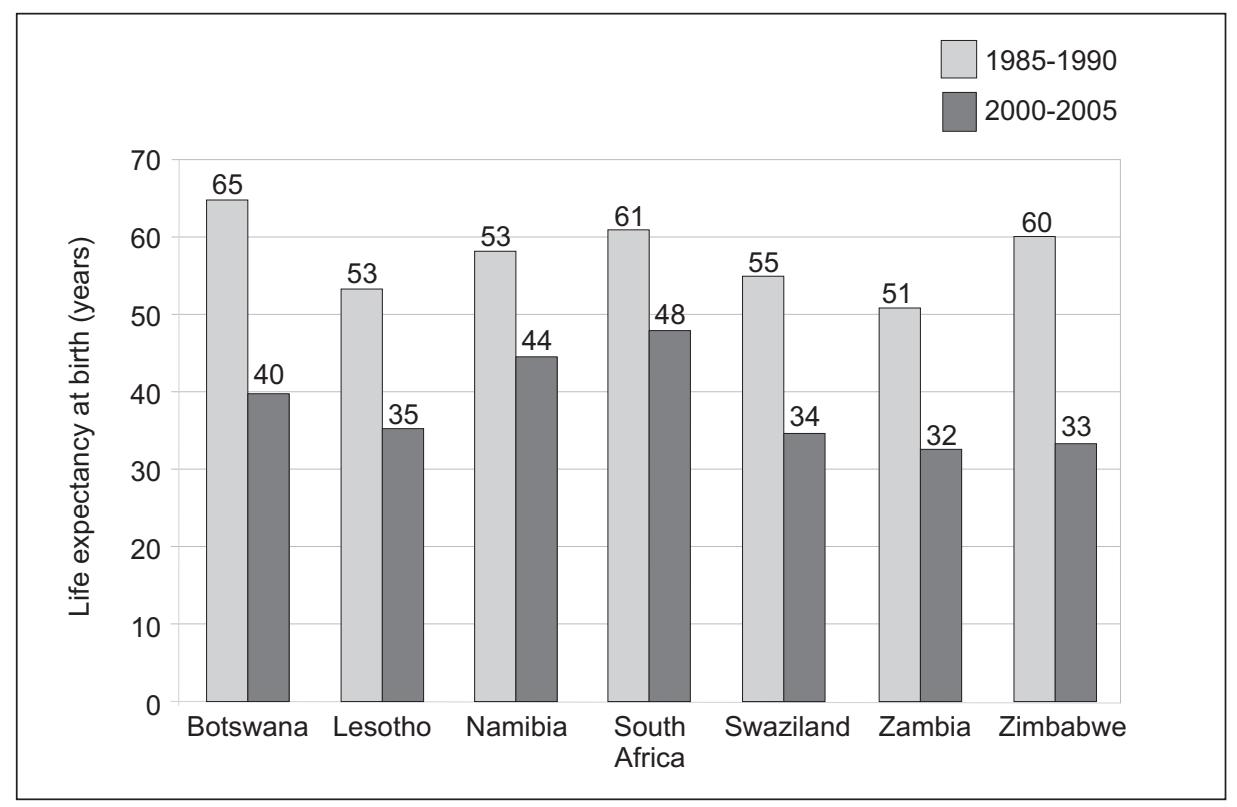

Figure 5.3 Life expectancy at birth in Botswana and other countries in the African region, 1985-1990 and 2000-2005

Source: DESA (2005)

40 years compared with a value of 65 years in the latter half of the 1980s. Figure 5.3 shows that other countries in the sub-Saharan region have also followed similar trends.

Taking a microeconomic perspective, we know that as economic growth decreases and HIV infected persons leave the labour force, household incomes will be affected. A fall in households' income will usually mean a redistribution of spending away from education and non-HIV related healthcare. Families and communities are therefore pushed further into poverty as often the sole provider or head of the household is the one who succumbs to HIV/AIDS. In the Pacific islands for example, where many seafarers support 6 to 8 people and in some cases up to 30 people, HIV/ AIDS-induced mortality can be a source of immense grief and hardship.

One of the now well-known effects of the HIV epidemic is the increasing number of orphans who are left behind when their parents / primary caregivers succumb to the disease. A United Nations report (DESA, 2005) placed the number of orphans at 15 million, of which 12 million resided in sub-Saharan Africa. In the Caribbean, there are approximately 250,000 orphans due to HIV/AIDS (UNDP, 2002), which is a significant number when compared with a population size of less than eight million persons. The orphaned children are usually rejected by family members due to the stigma attached to HIV and therefore become the responsibility of the state. The psychological impact of HIV/AIDS and the incidence of broken homes are expected to have long-term implications for the life and behaviour of orphaned children.

The need for programmes to address the rise in orphanhood will mean that countries in the fight against HIV/AIDS will be forced to redirect resources away from development programmes seeking to provide infrastructure, education and training, poverty reduction and healthcare. Moreover, this will be happening even as their ability to generate new income is being negatively affected by the epidemic. 


\subsection{Out of evil....?}

There is no question that the HIV/AIDS epidemic is an evil that has made an unwelcome visit to our civilisation. The issue is whether, out of this evil, some good can come. HIV/AIDS has no doubt become one of the greatest hurdles to countries as they aspire to economic and social development. However, the epidemic can also be seen as challenging countries and regions to survive and to strive even harder to succeed in achieving their economic and development goals. For one thing, the emergence of HIV/AIDS has resulted in the establishment of several agencies and organisations to provide assistance to developing countries in their efforts to eradicate this epidemic. This should be used as an opportunity by countries in these regions to broaden the base of their development support system and to strengthen the systematic weaknesses which have been highlighted by the HIV/AIDS epidemic. It will also be possible to learn from the experiences of countries that have had success in containing the impact of the epidemic on their development. Such interactions have made for the way for new and/or increased relations among countries of the world.

More important is the fact that what HIV/AIDS has done is to hold the mirror to the society, to reveal in stark relief features which cry out for self-examination and self-improvement. This holds true for the way in which some of our public institutions have operated, but it also holds true for the way in which we have responded to our fellow citizens affected by HIV/AIDS.

The epidemic has highlighted the need to balance the vulnerability of small countries with a resilience, which comes from better planning and from organising ourselves better. The vulnerability/resilience dichotomy is linked to the fact that every important social outcome reflects a combination of forces over which we have no control, as well as forces which reflect the choices and decisions we make. What HIV/AIDS has brought to the fore is the need to enhance the quality of our decision making.

The examination of the three regions has presented a number of best practices in the quest for successful response programmes:

- A policy to provide free, nationwide treatment and ARV drugs to all who require them has been in place in Botswana since 2001. Of course, free provision is not sufficient unless it is embedded within a broader range of policies and interventions.

- A comprehensive prevention programme that addresses the general population on one level and targets specific, vulnerable populations can be seen in the Caribbean.

- A commitment by leaders to HIV/AIDS response programmes, shown by a sustainable level of domestic budget funding, is the case in Botswana and Namibia.

- A regional approach to response initiatives, which pools financial and technical resources, an outstanding example of which is the Pan-Caribbean Partnership on HIV/AIDS (PANCAP) in the Caribbean.

- Involvement by the regional university to enhance the quality of collaboration in the response to HIV/AIDS, for example UWI HARP in the Caribbean, is certainly a model for other parts of the world.

The opportunities created by HIV/AIDS are mainly in areas where there is an immense need to improve the quality of policy design and implementation. Some of the areas mentioned in the studies include:

- The development and improvement of health information systems and national surveillance systems to track not only HIV/AIDS, but other health conditions,

- The development and enactment of policies and laws to deal with stigma and discrimination, 
- The development of response initiatives to include poverty reduction strategies since HIV/ AIDS has been linked to poverty,

- The development of programmes that increase the numbers of medical professionals trained and implement strategies to retain health sector workers, and

- The improvement of social services to respond more effectively to the needs of the socially displaced.

\subsection{Conclusion}

We have seen that the three regional experiences highlight a number of theme areas, study of which facilitates an improved understanding of the experience and impact of HIV/AIDS in small countries. These theme areas were shown to be:

Demography issues. We need to monitor the impact of the epidemic on the size and structure of populations. In the extreme case of very small countries with an uncontrolled epidemic, the possibility of extinction could not be ruled out.

Development impacts. The efforts by small countries to deal with problems of poverty and income distribution are severely hampered by the epidemic, suggesting that conscious efforts to protect gains in these areas need to be made. The epidemic has shown that the experience of possible stagnation or reversal of development cannot be ruled out.

Opportunities for modernisation. While the epidemic has posed a serious threat to the small countries surveyed, it also presented these countries with opportunities for improving their modus operandi. What is now clear is that it cannot be 'business as usual' in a period of HIV/ AIDS. The epidemic has shown the weaknesses in the social systems of these countries, but with the external support available countries can put emphasis on institutional strengthening to improve policy design and implementation in key areas. Small countries can also learn how to better make their case for special treatment in a world that seems poised to take up a devil-takethe-hindmost posture.

In this light it would be important that governments of developing countries, together with the international community, press for a more balanced TRIPS resolution that would not only value the protection and enforcement of intellectual property rights, but also the advancement of social and moral rights of many people in the developing world who have been affected by HIV/AIDS in one way or the other. This calls for radical changes in the granting of licences to access medications as many of the countries that have high prevalence rates of HIV/AIDS do not have fundamental manufacturing capacities under the compulsory licence arrangements. The scale of the devastating developmental effects of HIV/AIDS cannot be underestimated, and similarly the remedial role that generic drugs play in the fight against the disease cannot be undervalued. This then calls policymakers to bargain for a TRIPS agreement that is tailored to the country-specific needs.

In conclusion, while the studies have shown that small countries need to pay particular attention to the way HIV/AIDS impacts on their social and economic systems, and while they certainly cannot afford to simply hope for the epidemic to go away, it is important that small countries see in the epidemic the opportunity to upgrade the ways in which they carry out their normal affairs. They have to strive more than ever to make the very best use of the resources made available to fight off the epidemic, in particular, but also to find ways of using these resources to strengthen the development effort so urgently needed by their populations. 


\section{References}

DESA (2005). Population, Development and HIV/AIDS with Particular Emphasis on Poverty: The Concise Report. United Nations Department of Economic and Social Affairs, Population Division.

Garrett, Laurie (2005). HIV and National Security: Where are the Links? New York: Council on Foreign Relations.

McLean, Roger (2004). 'HIV/AIDS Economic Impact Study on Suriname', Health Economics Unit, UWI - a study completed under the European Union Institutional Strengthening Project, 2003-04.

UNDP (2002). HIV/AIDS Statistical Fact Sheet. Available at: www.undp.org/hiv/docs/olpubs/ Barcelona-statistical-fact-sheet-2July02.doc

US Census Bureau, Population Pyramids. Available at: http://www.census.gov/cgi-bin/ipc/idbpyrs. $\mathrm{pl}$ ?Cty=TD\&out=s\&ymax=200\&submit=Submit+Query 
